\title{
НОВЫЕ ПРЕДСТАВИТЕЛИ ПОЗДНЕМЕЛОВЫХ ГЕКСАКТИНЕЛЛИД (PORIFERA) РОССИИ И УКРАИНЫ
}

\section{Е.М. Первушов}

Саратовский государственный университет, кафедра исторической геологии и палеонтологии E-mail: pervushovem@mail.ru

Диагностированы остатки представителей семейств Coeloptychiidae (Umbrelliserus olferjevi, gen. et sp. nov., маастрихт, Россия) и Leptophragmidae (Turbiplana nerodenkoi, gen. et sp. nov., сеноман, Украина). Результаты изучения скелета описанных губок подтверждают установленные ранее общие тенденции в морфогенезе позднемеловых гексактинеллид и свидетельствуют о достоверности разработанных принципов систематики меловых представителей этой группы на уровне семейства.

New taxa of Hexactinellida (Porifera) from the Upper Cretaceous of Russia and Ukraine

\section{E.M. Pervushov}

New taxa of hexactinellid sponges: Umbrelliserus olferjevi, gen. et sp. nov. (Coeloptychiidae) from the Maastrichthyan of the Volga river basin, Russia and Turbiplana nerodenkoi, gen. et sp. nov. (Leptophragmidae) from the Cenomanian of Ukraine are described. Study of skeletal remains of the described sponges allows to confirm proposed earlier basic trends in morphogenesis of the Upper Cretaceous hexactinellids. It also is evidence of reliability of worked out principles of Cretaceous Hexactinellida systematic on a familial level.

Среди представленных коллегами сборов остатков скелетов позднемеловых гексактинеллид отдельные образцы, из сеномана юго-востока и маастрихта юго-запада Русской плиты, были выделены благодаря заметному своеобразию морфологии некоторых элементов скелета и дермальной скульптуры. Особый интерес к данным единичным экземплярам предопределен тем, что за несколько лет до этого мы предпринимали попытки определиться как в морфологии, так и с принципами систематики представителей семейств гексактинеллид (Coeloptychiidae, Leptophragmidae), к которым, по предварительному заключению, и принадлежат найденные формы.

Первоначальный опыт некого системного подхода при рассмотрении аспектов эволюционной морфологии был приобретен нами при изучении скелета весьма разнообразных и многочисленных представителей семейства Ventriculitidae [1]. Последующие исследования представителей семейств Coeloptychiidae и Leptophragmidae [2-4] показали мозаичность таксономической значимости тех или иных установленных признаков при систематических построениях на примере разных семейств и подотрядов. Обобщение результатов детального рассмотрения морфологии скелетных форм представителей семейств Ventriculitidae,

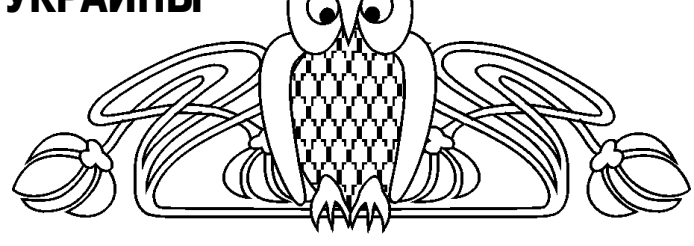

Coeloptychiidae и Leptophragmidae [5, 6] на основе весьма представительного ископаемого материала позволило высказать некие гипотетические представления по общим принципам построения классификаций семейств гексактинеллид. Тем самым до некоторой степени были представлены возможные вариации формообразования и развития тех или иных филогенетических ветвей в составе семейств гексактинеллид на протяжении мелового и палеогенового времени.

Описания новых представителей семейств Coeloptychiidae и Leptophragmidae, предложенные в данной работе, дополняют представления о разнообразии этих групп гексактинеллид, доказывая высказанные ранее предположения о тенденциях в их морфогенезе на протяжении альбского - палеоценового времени, и подтверждают достоверность общих принципов систематики меловых гексактинеллид.

1. Описанный сеноманский представитель лептофрагмид отличается архаичным построением дермальной скульптуры, при большой толщине стенки и значительных значениях общих параметров скелета. Скульптура как таковая - с дифференцированными элементами, как у многих позднемеловых гексактинеллид - у представителя этого рода еще не сформирована.

2. Изученный маастрихтский представитель цоелоптихиид характеризуется весьма ажурным, тонкостенным построением скелета с необычно большим количеством мелких субоскулюмов и своеобразным построением вторичной парагастральной полости.

3. Рассмотрение особенностей морфологии скелета и дермальной скульптуры описанных в работе представителей гексактинеллид подтверждает выявленные тенденции расселения губок в шельфовых морях востока Европейской палеобиогеографической области в альбе - сеномане и постепенной миграции скелетных гексактинеллид из мелководных прибрежных зон в относительно глубоководные участки бассейнов, начиная с позднего сантона до маастрихта и палеоцена.

4. Представления о систематическом положении новых таксонов дополняют ранее предложенные схемы классификаций семейств Coeloptychiidae и Leptophragmidae [5, 6], подтверждая достоверность и целостность разрабатываемых принципов систематики гексактинеллид. 
5. Доступный к настоящему времени ископаемый материал представляется достаточным для выделения среди позднемезозойских гексактинеллид условных групп, представители которых характеризуют собой отдельные этапы становления морфотипов скелетных гексактинеллид. Представляется, что изменения в морфологии и параметров многих элементов скелета, ирригационной системы и скульптуры гексактинеллид взаимообусловлены. На протяжении позднемезозойской истории видоизменения габитуса скелета и дермальной скульптуры, в частности, носили обусловленный и порой направленный характер, вслед за изменением доминирующих параметров водной среды в пределах бассейнов. Условные группы с «архетипным», «мезотипным» и «кайнотипным» строением габитуса скелета и дермальной скульптуры характеризуют отдельные этапы филогенеза значительной части гексактинеллид.

Так, «архетипные» формы известны со среднеюрского по альбское - сеноманское время. К этой группе можно отнести и описанного в статье представителя лептофрагмид. «Мезотипные» гексактинеллиды больше известны с позднеюрского по сантонское время, в качестве типичных представителей можно рассматривать многих вентрикулитид (Napaeana, Lepidopsongia). «Кайнотипные» представители группы, к которым можно отнести и проанализированного в работе представителя цоелоптихиид, доминируют в структуре гексактинеллид начиная с позднесантонского - кампанского времени. Вероятно, в соответствии с типом строения скелета были предопределены возможности губок по реализации тех или иных вариаций морфотипов скелетных гексактинеллид, в том числе различных уровней модульной организации - автономий, транситорных и колониальных форм. Оба новых таксона рассматриваются в качестве представителей первичных (Leptophragmidae) и вторичных (Coeloptychiidae) транситорных форм [5].

Мы приносим свою искреннюю благодарность А.Г. Олферьеву за консультации по вопросам стратиграфии верхнемеловых отложений Поволжья, совместные полевые изыскания и предоставленные многочисленные материалы по ископаемой спонгиофауне, а также В.Б.Сельцеру, с поразительным постоянством представляющему находки весьма оригинальных остатков губок из разных интервалов пород мелового возраста.

Тип (Класс) Hexactinellida Smidt, 1869 Подотряд Lychniscina Schrammen, 1936 Семейство Coeloptychiidae Goldfuss, 1833

Д и а г н о з. Тонкостенные скелеты губок плициформного строения. Дермальная и парагастральная скульптура отсутствует, кортикальный покров развит у некоторых форм на поверхности верхнего края с нерегулярно распространенными тонкими отверстиями. Ирригационная система состоит из коротких и тонких апо- и прозохет, иногда отдельные ее элементы слабо проявлены. Интерканалярная спикульная решетка, составляющая скелетообразующую стенку, отличается правильным построением крупных кубических, реже прямоугольных, спикульных клетей.

С о с т а в. Два подсемейства: Coeloptychiinae Goldfuss, 1833; Callodictyoninae Perv., 2002.

С р а в н е н и е. От Camerospongiidae отличается преимущественно плициформным строением скелета, а от Ventriculitidae, кроме того, и практическим отсутствием элементов скульптуры и ирригационной системы.

С о х р а н н о с т ь. Из более 150 экземпляров, главным образом представителей подсемейства Coeloptychiinae, больше половины (90 экз.) - это фрагменты скелета, чаще всего - половинки или сектора отворота лопастей. 1833

Подсемейство Coeloptychiinae Goldfuss,

Д и а г н о з. Губки транситорного уровня организации, скелеты исходно плициформного строения, характерно развитие субоскулюмов на перегибах лопастей или на коленообразных изгибах субветвистых форм.

С о с т а в. Две трибы: Coeloptychiini Goldfuss, 1833 и Spirospongiini Perv., 2002.

С р а в н е н и е. От Callodictyoninae отличается наличием субоскулюмов.

Р а с п р о т р а н е н и е. Верхний мел Европы.

\section{Триба Coeloptychiini Goldfuss, 1833}

Д и а г н о з. Скелеты плициформные и фавосиформные, с вторичной парагастральной полостью, образованной при отвороте лопастей.

С о с т а в. Три подтрибы: Coeloptychiina Goldfuss, 1833; Myrmecioptychiina Perv., 2002; Petrosifavosina Perv., 2002.

С р а в н е н и е. От Spirospongiini отличается наличием вторичной полости.

Р а с п р о с т р а н е н и е. Верхний мел, (?) сеноман, турон - маастрихт Европы.

\section{Подтриба Coeloptychiina Goldfuss, 1833}

Д и а г н о з. Плициформные скелеты с вторичной парагастральной полостью. Лопасти, образующие коническое стержнеобразное основание скелета, дихотомируют при отвороте, образуя грибо- или зонтикообразную верхнюю часть скелета. Лопасти неоднократно дихотомируют, составляя широкую площадь отворота. Субоскулюмы круглые, у кампанских форм - более овальные и даже щелевидные, обычно их размеры увеличиваются от основания к верхнему краю. Поверхность верхнего края в виде сплошной лентообразной поверхности или в виде обособленных участков лопастей. Над первичной щелевидной парагастральной полостью в оскулярной мембране проявлены оскулярные отверстия. 
Состав. Четыре рода. Coeloptychium Goldfuss, 1833; Troegerella Ulbrich, 1974; Foliscyphia Perv., 2002; Umbrelliserus gen. nov.

С р а в н е н и е. От Myrmecioptychiina отличается отсутствием дополнительных субоскулюмов на поверхности верхнего края и наличием оскулярных отверстий над первичным щелевидным парагастром.

Р а с п р о с т р а н е н и е. Верхний мел, (?) сеноман, турон - маастрихт Европы.

Род Umbrelliserus, gen. nov.

Н а з в ан и е рода от umbrella лат. - зонт, serus лат. - поздний.

Т и п о в о й в и д-Umbrelliserus olferjevi, sp. nov. Верхний мел, сеноман. Украина.

Д и а г н о з. Скульптура вторичной парагастральной полости на участке отворота представлена извилистыми, дихотомирующими полосами щелевидных первичных оскулюмов, перекрытых мембраной. В структуре мембраны каждого оскулюма прослеживается один ряд поперечных узких миндалевидных оскулярных отверстий (табл. I, фиг. 18-2), длина которых совпадает с шириной первичного оскулюма. Поверхность верхнего края узкая, линейная.

С о с т а в. Типовой вид.

С р а в н е н и е. От Coeloptychium отличается строением скульптуры вторичной парагастральной полости, очень узким, линейным построением поверхности верхнего края и меньшим значением диаметра субоскулюмов, с чем связывается значительно большее количество субоскулюмов в структуре скелета. От Troegerella и Foliscyphia отличается также сплошным построением линии верхнего края.

Р а с п р о с т р а н е н и е. Маастрихт юговостока Русской плиты.

\section{Umbrelliserus olferjevi, sp. nov.}

Табл. I, фиг. $1-2$

Н а 3 в а н и е в и д а в честь геологастратиграфа А.Г. Олферьева.

Г о л о т и п-Экз. СГУ № 122/4801; с. Рыбное, Вольский район Саратовской области. Верхний мел, верхние интервалы нижнего маастрихта.

O п и с а н и е. Скелет вторично плициформный, грибо-зонтикообразный. Толщина стенки 1-1,5 мм. Диаметр вторичной парагастральной полости, судя по сохранившемуся сегменту (радиус 70 мм), достигал 120-130 мм. Ширина фрагмента 88 мм. Толщина скелета в пределах отворота максимальна в средней его части и составляет 14-15 мм. Поверхность вторичной парагастральной полости пологая выпуклая в средней части, сложена многочисленными радиальными дихотомирующими извилистыми выпуклыми валиками и сопряженными бороздами щелевидных первичных оскулюмов. Размеры оскулярных отверстий в структуре мембраны, варьируют в пределах изменения значений ширины оскулюма - 1-1,5/2,5-4 мм. Маргинальные участи вторичной парагастральной поверхности выражены в виде узкого субплоского уступа без скульптуры (табл. I, фиг. 1 в, e). В этом случае верхний край - это узкая линия между верхней и нижней (дермальной) поверхностями отворота. Нижняя поверхность отворота почти плоская, полого вогнутая. В пределах описываемого образца прослеживается пять первичных лопастей, длиной до 65 мм. Высота лопастей 6-7 мм, ширина - 4,5-5 мм, выделяется два - три узла дихотомии лопастей. На овально-выпуклой поверхности лопастей отчетливо прослеживаются многочисленные округлые, реже овальные, субоскулюмы, которые морфологически почти не обособлены. Диаметр субоскулюмов 1,5-2 мм, его значение обычно сопоставимо со значением расстояния между субоскулюмами на одной лопасти. На поверхности первичной лопасти, с дихотомирующими составляющими, обычно выделяется до 30 субоскулюмов. На поверхности данного фрагмента обнаружено около 130 субоскулюмов, а структуре скелета полной сохранности их общее количество могло достигать 350-500. Ширина сопряженных борозд 4-5 мм, их глубина максимальна в средней части отворота.

С р а в н е н и е. Типовой вид.

3 а м е ч а н и е. Фрагмент отворота, верхней части грибовидного скелета, примерно соответствующий $1 / 4$ от общей площади отворота (табл. I, фиг. $2 a$ ). Скелет выполнен опалом и халцедоном, частично - марказитом. Поверхности сколов рецентные.

Р а с п р о с т р а н е н и е. Как у голотипа.

М а т е ри а л. Голотип. 1833)

Подотряд Hexactinina Schrammen, 1936

Семейство Leptophragmidae (Goldfuss,

Д и а г н о з. Тонкостенные скелеты исходно париформных и плициформных губок. Скульптура реактивная, равномерно рассеянная, сотовая. Апо- и прозопоры мелкие, круглые и реже овальные, по размерам равны узлам ребер и реже - ребрам. Ирригационная система представлена плотно расположенными мелкими поперечными субцилиндрическими слепыми апо- и прозохетами. Интерканалярная решетка из мелких субпризматических клетей, продольно ориентированных, в поперечном сечении часто ромбовидных и субтреугольных, обычно формирует веерообразные сектора по поверхности скелета и редко составляет правильную решетку. Каналярный скелет не развит. Паренхимальная спикульная решетка обнаруживается в нижней трети высоты парагастра плициформных лептофрагмид. Развит дермальный и парагастральный кортекс.

С о с т а в. Два подсемейства: Leptophragminae (Goldfuss, 1833) и Guettardiscyphiinae Pervushov, 1997

Р а с п р о с т р а н н и е. (?) Юра, мел, (?) палеоген Европы. 


\section{7}

Подсемейство Guettardiscyphiinae Pervushov,

Д и а г н о з. Скелет исходно плициформный, видоизмененный до колюминарного и ветвистого, по одной или по обеим поверхностям перегиба лопастей, в том числе и обособленных, развиты субоскулюмы.

С р а в н е н и е. От Leptophragminae отличаются плициформным скелетом и транситорным уровнем организации - наличием субоскулюмов на перегибах лопастей; обычно большей толщиной стенки и меньшим количеством прозопор.

Р а с п р о с т р а н е н и е. (?) Альб, сеноман - маастрихт Европы.

С о с т а в. Две трибы: Guettardiscyphiini Perv., 1997; Balantionellini Perv., 1999.

Триба Guettardiscyphiini Pervushov, 1997

Д и а г н о з. Щелевидная, многолопастная парагастральная полость сопряжена субоскулюмами, которые расположены на перегибе лопастей или реже выражены в виде обособленных поперечных выростов.

С p а в н е н и е. От представителей Balantionellini отличаются исходно плициформным построением скелета, когда субоскулюмы в основном расположены на перегибах лопастей.

Р а с п р ос т р а н н и е. (?) Альб, верхний мел, эоцен Европы.

С о с т а в. Две подтрибы. Guettardiscyphiina Perv., 1997; Crassiscyphiina Perv., 1997.

\section{7}

Подтриба Guettardiscyphiina Pervushov,

Д и а г н о з. Лопасти развиты радиально от центральной, осевой, части скелета или поперечно и диагонально несущей лопасти и с возрастом обособляются. Размеры субоскулюмов и расстояние между ними увеличивается по направлению вверх. Прозопоры расположены в диагональных или продольных рядах. Щелевидный оскулюм закрыт мембраной с оскулярными отверстиями. Плоские участки стенки с полусекториальным рисунком кортекса, а на перегибах лопастей - линейное, продольное положение призматических клетей.

С ос т а в. Пять родов: Guettardiscyphia Mantell, 1822; Pleurostoma Roemer, 1864; Koleostoma Regnard, 1926; Ceniplaniscyphia Perv., 1997; Turbiplanum, gen. nov.

С ра в н е н и е. От Crassiscyphiina отличается равномерно - линейным расположением мелких элементов дермальной скульптуры.

Р а с п р о с т р а н е н и е. (?) Альб, сеноман - маастрихт, (?) эоцен Европы.

Род Turbiplana, gen. nov.

Название рода от turba лат. - неурядица, беспорядок, planus лат. - поверхность.

Т и п о в о й в и д-Turbiplana nerodenkoi, sp. nov. Верхний мел, сеноман. Украина.

Д и а г н о з. Построение дермальной скульптуры хаотичного типа: спутанное паутинное расположение разно ориентированных позитивных элементов при доминировании остий различных полигональных очертаний и разного размера - до 1-2 мм (табл. III, фиг. 1). На $1 \mathrm{~cm}^{2}$ приходится около 20-25 прозопор. Толщина стенки 4-5 мм. Очень крупные, единичные, субоскулюмы на перегибах лопастей.

С о с т а в. Типовой вид.

С р а в н е н и е. От Guettardiscyphia и Pleurostoma отличается строением дермальной скульптуры (табл. III) и значительно меньшей плотностью расположения прозор, от Koleostoma - очертаниями и размерами субоскулюмов, от Ceniplaniscyphia - наличием дермальной скульптуры.

Р а с п р о с т р а н е и е. Сеноман юго-запада Русской плиты.

3 а м е ч а н и я. Особенности построения дермальной скульптуры, количество, очертания и размеры субоскулюмов позволяют предположить, что рассматриваемый таксон может представлять собой отдельную ветвь развития в составе лептофрагмид на уровне подтрибы, по аналогии с представителями рода Crassiscyphia Perv., 1997 $[5,6]$.

Turbiplana nerodenkoi, sp.nov.

Табл. II, фиг. 1; Табл. III, фиг. 1

Н а з в а н и е в и д а в честь украинского геолога В.М. Нероденко.

Г о л о т и п - Экз. СГУ № 122/14798; бассейн р. Рать, карьер в окрестностях Безобразово, Украина. Верхний мел, сеноман.

О п и с а н и е. Монолопастной, едва изогнутый скелет, в виде плоского широкого асимметричного конуса. Высота скелета 90 мм. Диаметр бокала по верхнему краю 21-25/более 120 мм, диаметр щелевидного оскулюма 10-14/110 мм. Диаметр скелета в его основании - 21/29 мм. Отчетливо выраженная площадка прикрепления вогнутая, неровная, размером 21/36 мм. На перегибах лопасти расположено по два крупных субоскулюма. На поверхности более протяженного и полого наклонного перегиба субоскулюмы наиболее крупные (7,5-88/9-11 мм), а на противоположном участке более крутого положения перегиба лопасти диаметр субоскулюмов 6 мм.

С р а в н е н и е. Типовой вид.

Р а с п р о с т р а н е н и е. Как у голотипа.

М а т е р и а л. Голотип.

Работа выполнена при поддержке РФФИ (грант 06-05-64878-a) 

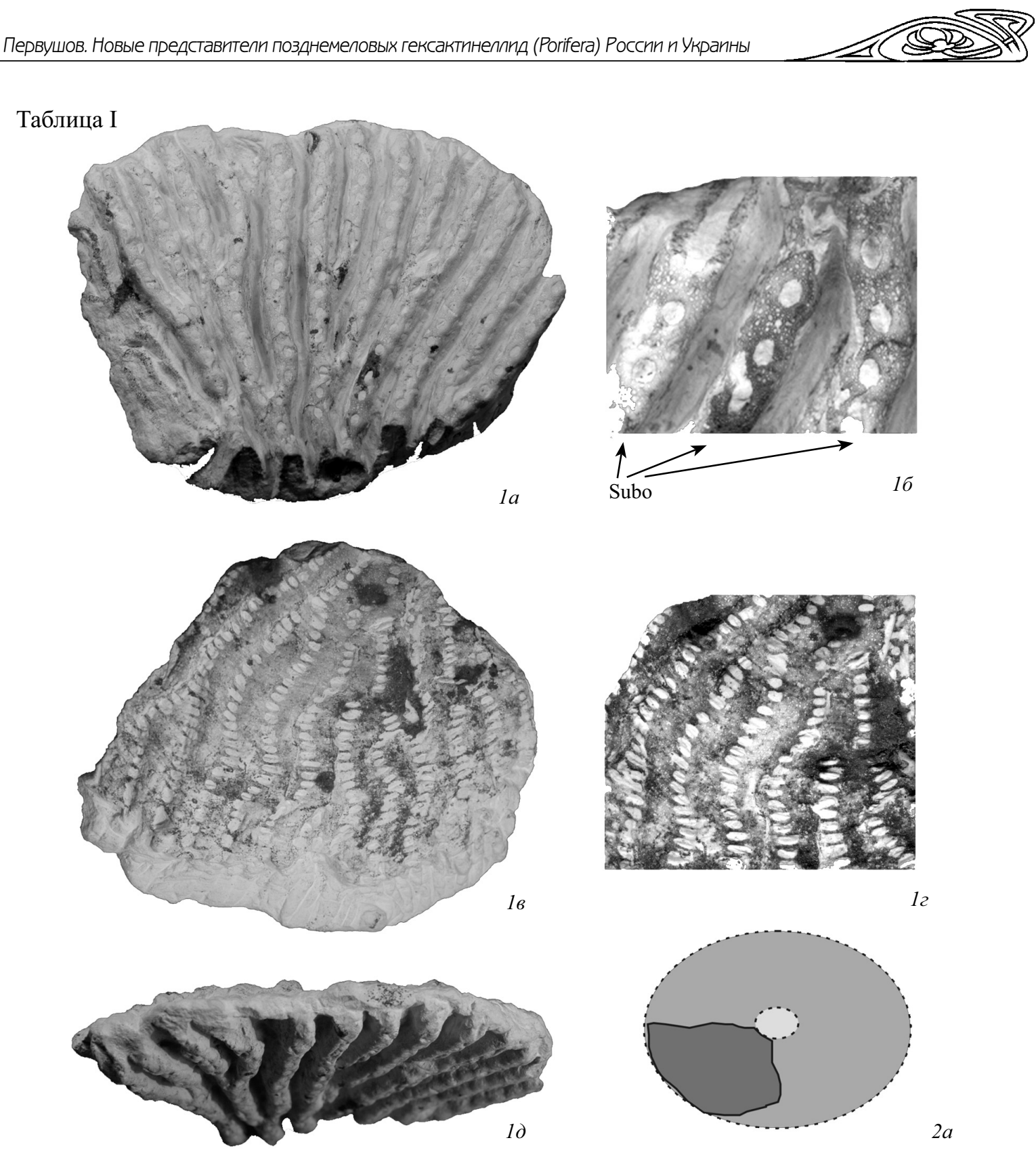

12
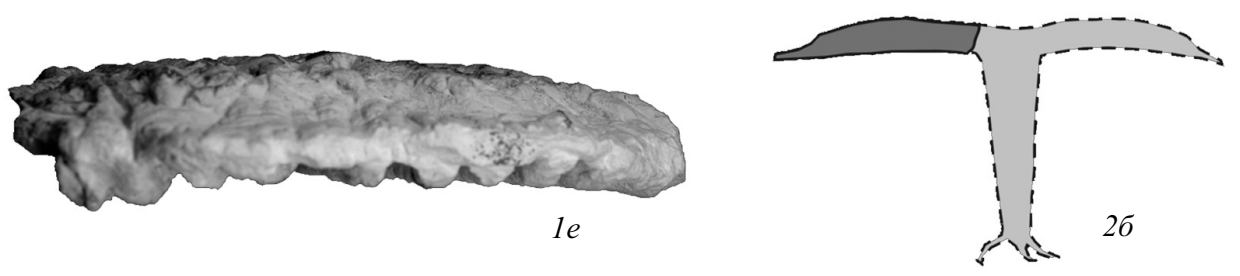

Фиг. 1. Umbrelliserus olferjevi, sp. nov.; Экз. СГУ, № 122/4801: с. Рыбное, Вольский район Саратовской области. Верхний мел, верхние интервалы нижнего маастрихта: $1 a-$ вид снизу, дихотомирующие лопасти с тонкими субоскулюмами на их поверхности разделены глубокими асимметричными бороздами $(\mathrm{x} 0,9) ; 16-$ снизу $(\mathrm{x} 2,5)$, субоскулюмы на поверхности лопастей и заметно хаотичное расположение прозопор; 1 в - сверху, сегмент вторичной парагастральной полости (х0,9); 12 - сверху (х2,0), прослеживаются ряды щелевидных оскулярных отверстий; $1 \partial$ - вид на маргинальную поверхность верхнего края и нижнюю поверхность отворота - дихотомирующие ребра $(x 0,9) ; 1 e-$ вид на фрагмент отворота сбоку, на маргинальную поверхность верхнего края $(\mathrm{x} 0,9)$.

Фиг. 2. Umbrelliserus olferjevi, sp. nov.; реконструкция скелета; $2 a$ - вид сверху, на вторичную парагастральную полость; 26 - вид сбоку; светлосерое - предполагаемые очертания скелета полной сохранности, темно-серое - описанный фрагмент скелета.

Условные обозначения: Subo - субоскулюм. 

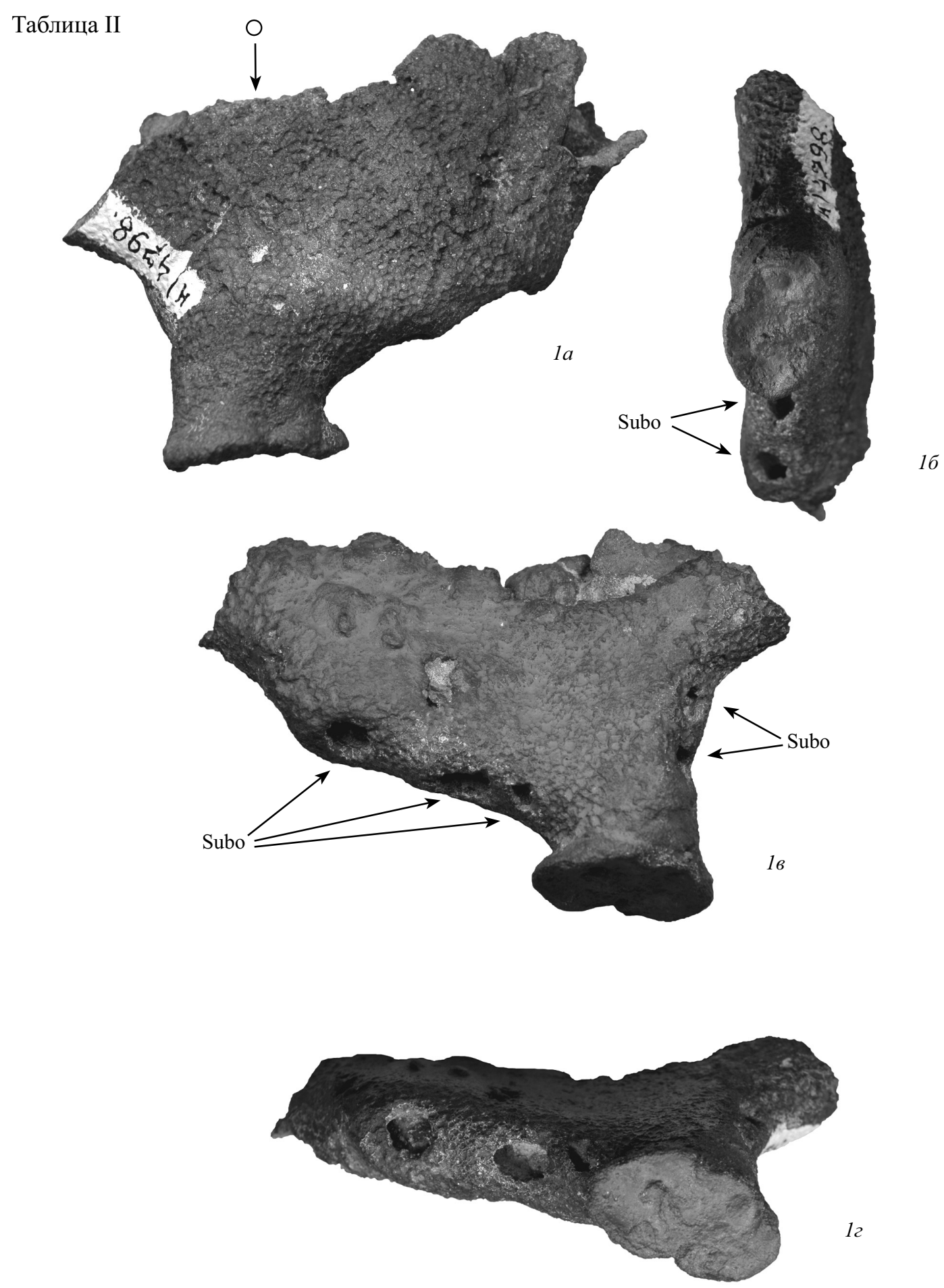

Фиг. 1. Turbiplana nerodenki, sp. nov.; Экз. СГУ, № 122/4798 (х0,75): бассейн р. Рать, карьер в окрестностях с. Безобразово, Украина. Верхний мел, сеноман. la, 1в - вид с противоположных широких (латусных) поверхностей лопастевидного скелета; 16 - вид снизу, видны крупные субоскулюмы; 12 - вид на узкие (ангустатные) поверхности скелета с субоскулюмами и на основание скелета.

Условные обозначения: О - оскулюм, Subo - субоскулюм. 


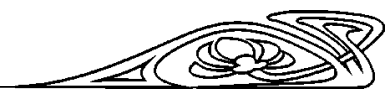

\section{Таблица III}
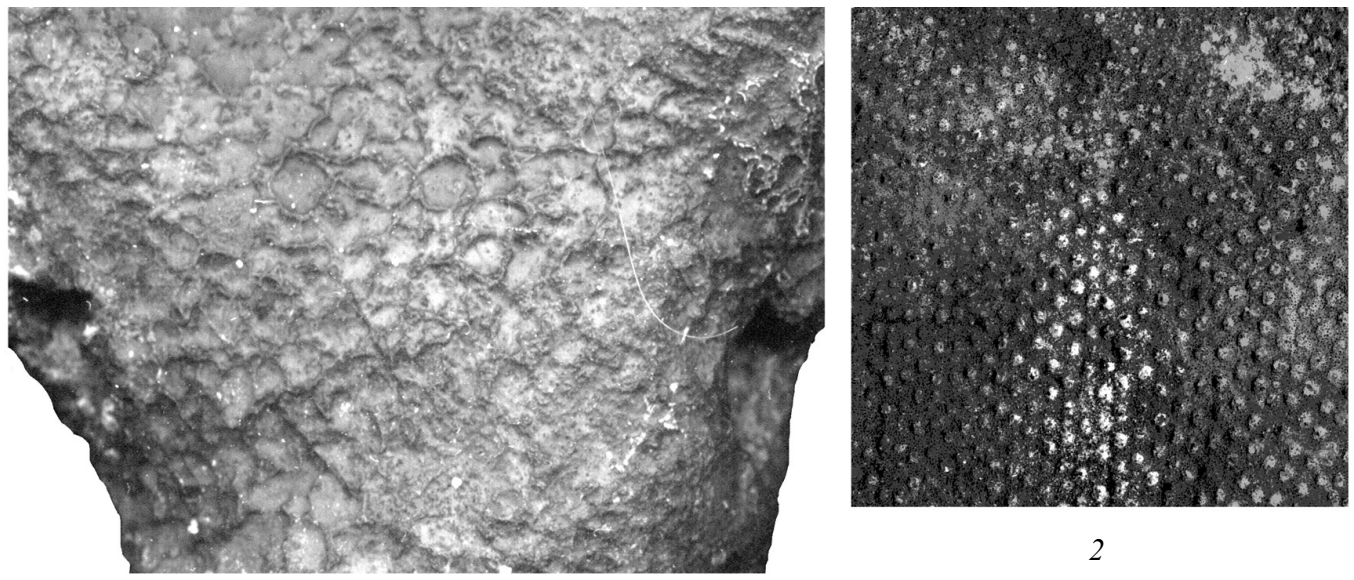

2
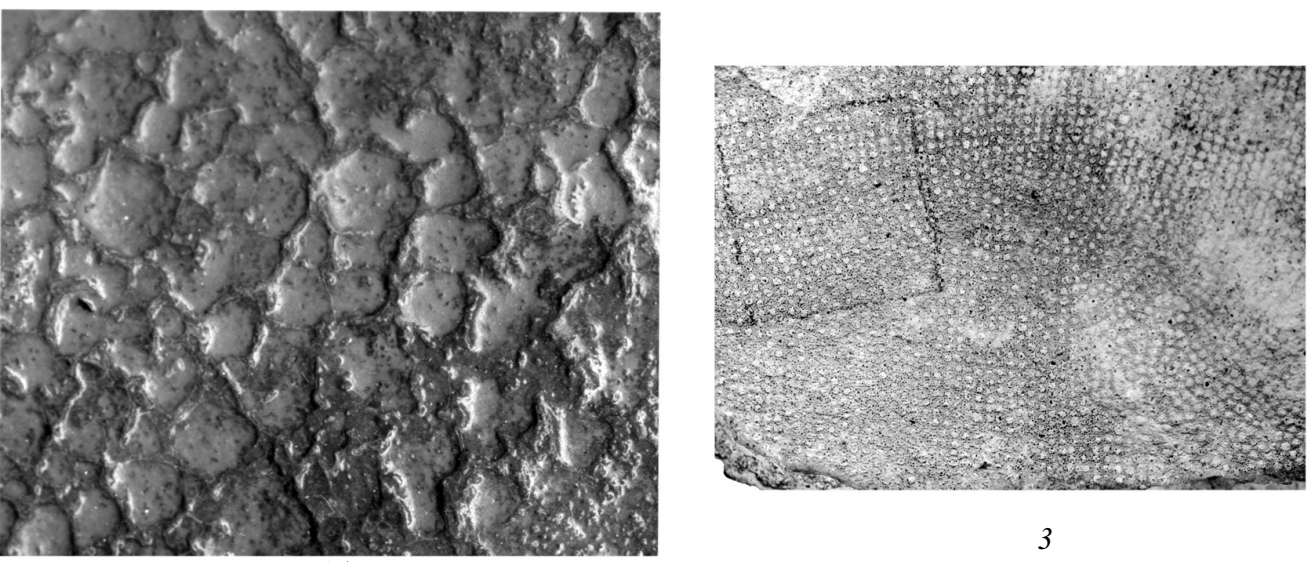

3

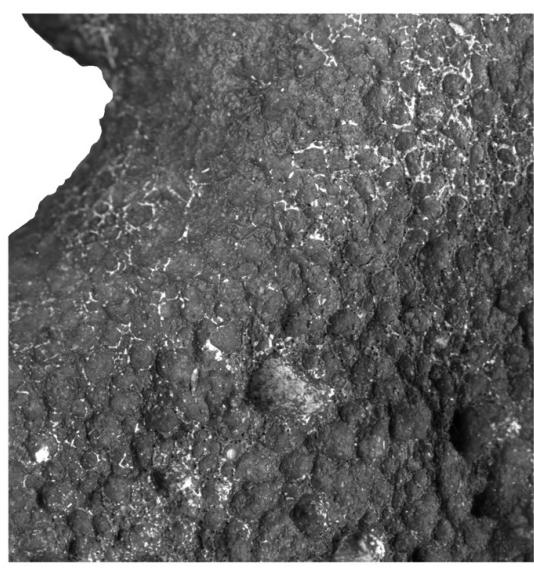

16

Фиг. 1. Turbiplana nerodenki, sp. nov.; Экз. СГУ, № 122/4798: бассейн р. Рать, карьер в окрестностях с. Безобразово, Украина. Верхний мел, сеноман. Строение дермальной скульптуры: $l a$, 1 в - в основании скелета, на противоположных латусных поверхностях (х2,5); 16 - прозопоры полигональных очертаний и разной размерности, позитивные элементы не явно выражены и не обособлены (х5).

Фиг. 2. Guettardiscyphia sp. ind.; Экз. СГУ, № 122/1710 (х4): строение дермальной скуль-

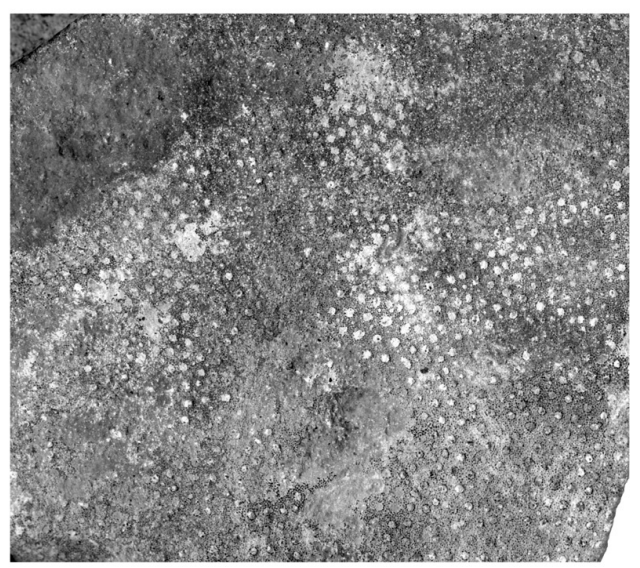

птуры по фрагменту лопасти г. Саратов, карьер «Заплатиновка», нижний сантон.

Фиг. 3. Guettardiscyphia sp. ind.; Экз. СГУ, № 121/156 (х2): особенности строения дермальной скульптуры по фрагменту лопасти; г. Саратов, карьер «Агафоновка», сантон.

Фиг. 4. Guettardiscyphia sp. ind.; Экз. СГУ, № 121/1497 (х2,5): строение дермальной скульптуры по фрагменту лопасти; г. Саратов, карьер «Агафоновка», нижний сантон. 


\section{Библиографический список}

1. Первушов Е.М. Позднемеловые вентрикулитидные губки Поволжья // Тр. НИИ геологии Сарат. гос. ун-та. Саратов, 1998. Т. 2. 168 с.

2. Первушов Е.М. Классификация семейства Leptophragmidae Goldfuss, 1833 (Porifera, Hexactinellida) // Учен. зап. геол. фак. Сарат. гос. ун-та. Нов. серия. 1997. Вып. 1. C. $32-44$.

3. Первушов Е.М. Род Balantionella Schrammen, 1902: coстав и филогенез // Тр. Науч.-исслед. ин-та геологии СГУ им. Н.Г. Чернышевского. Нов. серия. Саратов, 1999. Т. 1. C. $107-111$.

4. Первушов Е.M. Филогенез представителей семейств

УДК $552.541+551.2(470.45)$

\section{КАРБОНАТНЫЕ КОНКРЕЦИИ В СРЕДНЕЮРСКОМ РАЗРЕЗЕ НИЖНЕГО ПОВОЛЖЬЯ}

\section{В.Ф. Салтыков}

Саратовский государственный университет, лаборатория петрофизики

E-mail:dekanat@geol.sgu.ru

Изучены карбонатные конкреции, образующие многочисленные линзовидные цепочки различной протяженности на каждом гипсометрическом уровне среди среднеюрских пород. В отличие от существующего мнения о сидеритовом составе конкреций доказывается преобладающее развитие кальцита с разным участием сидерита и глинистого вещества. Вещественный состав конкреций характеризуется значительными колебаниями слагающих минералов. Для каждой свиты установлены свои особенности минерального и химического состава, а также специфические текстуры. Приведенные данные позволяют использовать карбонатные конкреции в качестве дополнительных признаков при расчленении разреза. Рассмотрены условия их формирования в процессе осадочной седиментации на территории Нижнего Поволжья в течение среднеюрской эпохи.

\section{Carbonate Nodules in the Middle Jurassic Section from the Lower Volga Region}

\section{V.F. Saltykov}

Carbonate nodules have been examined - those forming numerous lenticular chains of diverse lengths at each hypsometric level in the Middle Jurassic deposites. Contrary to the current view of the siderite composition of the nodules, dominant calcite development is proved, with siderite and clay matter involved. The material composition of the nodules is characterized by substantial variations of the component concentrations. Inherent peculiarities of the mineral and of the chemical compositions have been revealed in each suite, alongside with specific textures. The data presented here, makes it possible to use carbonate nodules as additional features in the section division. The conditions of their formation in the course of the Middle Jurassic sedimentation have been considered over the Lower Volga Region.
Coeloptychiidae и Leptophragmidae (Hexactinellida) // Tp. Науч.-исслед. ин-та геологии СГУ им. Н.Г. Чернышевского. Нов. серия. Саратов, 2001. T. VIII. С. 5-14.

5. Первушов Е.M. Позднемеловые скелетные гексактинеллиды России. Ч. II. Морфология и уровни организации. Семейство Ventriculitidae (Phillips, 1875), partim; семейство Coeloptychiidae Goldfuss, 1833 (Lychniscosa); семейство Leptophragmidae (Goldfuss, 1833) - (Hexactinosa) / Отв. ред. д-р геол.-минерал. наук В.Г.Очев. Саратов, 2002. 274 с., ил. (Тр. Науч.-исслед. ин-та геологии Сарат. гос. ун-та им. Н.Г.Чернышевского. Нов. серия. Т. ХІІ).

6. Первушов Е.M. Принципы систематики ископаемых скелетных губок - гексактинеллид // Изв. Сарат. ун-та. Нов. серия. Саратов, 2003. Т. 3, вып. 2. С. 144-155.

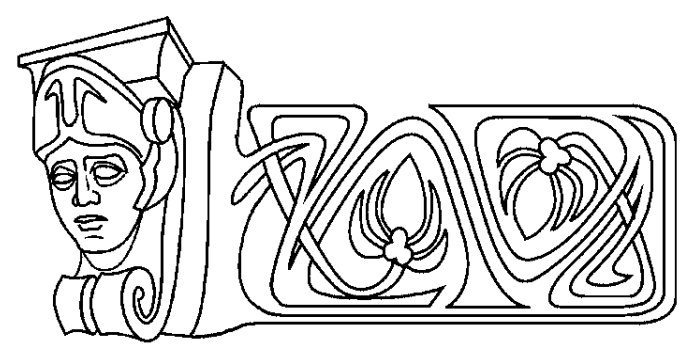

\section{Введение}

На протяжении почти столетнего изучения среднеюрских отложений Поволжья традиционно считалось, что среди глин распространены сидеритовые конкреции. А.Н.Мазарович [1] именовал их то сидеритами, то известковистыми песчаниками. Г.Ф. Лунгерсгаузен [2] называл их сидеритами без какого-либо обоснования лабораторными анализами. А.В.Смирнов [3] в результате изучения керна скважин в Волгоградской области вы-делял два горизонта: нижний глинисто-сидеритовый и верхний глинисто-известняковый, прослеженные на значительные расстояния. А.Г.Олферьев [4] среди жирновских глин указывал на присутствие крупных конкреций сидерита, а в келловейских глинах карбонатных стяжений (мергелей, известковистых песчаников). Описывая местные стратиграфические подразделения средней юры, В.И.Левина и Н.П.Прохорова [5] в жирновской свите отмечали прослои и линзы темно-серых известняков, в каменноовражной свите - линзы мергелей, в келловейских отложениях - глинисто-карбонатные конкреции.

Эта неопределенность минерального и химического состава карбонатных конкреций без указания их надежных отличий обусловила необходимость их подробного изучения с целью установления особенностей изменений их вещественного состава и текстур по всему разрезу с обозначением их стратиграфического положения. Следует отметить, что А.Н.Мазарович [1] был первым геологом, обратившим внимание на существование текстуры конус в конус в верхах выделенной им караулинской свиты, что впоследствии не получило своего отражения в публикациях. 